\title{
Research on solutions for connecting to marginal fields at Cuu Long basin to process and transport the products basing on existing petroleum technology and equipment
}

\author{
Thinh Van Nguyen * \\ Hanoi University of Mining and Geology, Hanoi, Vietnam
}

ARTICLE INFO

Article history:

Received $12^{\text {th }}$ Feb. 2021

Revised 14th May 2021

Accepted $10^{\text {th }}$ June 2021

Keywords:

Flow assurance,

Gathering and transportation,

Marginal oil field.
ABSTRACT

The Cuu Long basin is equiped with infrastructures and processing facilities serving for large-scale crude oil drilling and production operations. However, most of resevoirs in this area are now depleted, it means that they have reached their peaks and started to undergo decreasing productivity, which lead to a noticable excess capicity of equipment. In order to benefit from those declined oil fieds and maximize performance of platforms, solutions to connect marginal fields have been suggested and employed. Of which, connecting Ca Ngu Vang wellhead platform to the CPP-3 at Bach Ho oil field; platforms RC-04 and RC-DM at Nam Rong - Doi Moi oil filed to RC-1 platform at Rong oil field; wellhead platforms at Hai Su Den and Hai Su Trang oil fields to H4-TGT platform at Te Giac Trang oil field are typical examples of success. Optimistic achivements gained recently urges us to carry out this work with the aim to improve oil production of small reserves and to make best use of existing petroleum technology and equipment at the basin. Results of the research contribute an important part in the commence of producing small-scale oil deposits economically.

Copyright (C) 2021 Hanoi University of Mining and Geology. All rights reserved.

${ }^{*}$ Corresponding author

E - mail: nguyenvanthinh@humg.edu.vn

DOI: 10.46326/JMES.2021.62(3a).08 


\title{
Tạp chí Khoa học Kỹ thuật Mỏ - Địa chất
}

\section{Nghiên cứu giải pháp kết nối các mỏ cận biên tại bể Cửu Long để xử lý và vận chuyển sản phẩm dựa trên hệ thống công nghệ, thiết bị khai thác hiện có}

\author{
Nguyễn Văn Thịnh* \\ Trường Đại học Mỏ-Địa chất , Hà Nội , Việt Nam
}

THÔNG TIN BÀI BÁO T TÓM TẮT

Quá trình:

Nhận bài 12/02/2021

Sưa xong 14/5/2021

Chấp nhận đăng 10/6/2021

Tù̀ khóa:

Bảo đảm dòng chảy,

Mỏ cận biên,

Thu gom vận chuyển.
Hiện nay, tại Bể Cưu Long đang có một hệ thống lớn gồm cơ sở hạ tầng công trình biển và thiết bi xử lý phuc vụ cho hoạt động khai thác dầu khí. Tuy nhiên, phần lớn các mỏ đang khai thác đã trải qua giai đoạn khai thác đỉnh cao và đang ở giai đoạn suy thoái sản lượng, dẫn tới du công suất dư của thiết bị. Giải pháp phát triến kết nối các mỏ nhỏ vào hệ thống thiết bị sẵn có ở lân cận đã được triển khai áp dung hiệu quả đối với các mỏ nhu Giàn đầu giếng Cá Ngù̀ Vàng kết nối về giàn công nghệ trung tâm số 3 (CPP-3) mỏ Bach Hồ; các giàn nhe RC-04 và RC-DM thuộc mỏ Nam Rồng - Đồi Mồi kết nối về giàn $R C-1$ thuộc hệ thống thiết bị mỏ Rồng; các giàn đầu giếng mỏ Hải Su Đen, Hải Su Trắng kết nối về giàn H4-TGT thuộc hẹ thống thiết bi khai thác mỏ Tê Giác Trắng,... Trên cơ sở các kết quả đã đạt đươơc, việc nghiền cúu khả năng sử dụng công nghệ và hệ thống thiêt bị sẵn có để kết nối các mỏ mói, nhằm gia tăng hiệu quả sử dung thiết bị và giảm chi phí. Bài báo trình bày một số giải pháp kết nối hiệu quả các mỏ cận biên trong quá trình thu gom, xử lý và vận chuyển sản phẩm, nhằm sử dụng triệt để các thiết bị công nghệ sắn có của các mỏ hiênn hứu. Kết quả nghiên cúu sẽ là tiền đề cho việc đưa các phát hiên, cấu tạo dầu khí nhỏ trong tương lai vào khai thác, mang lại hiệu quả kinh tếcao.

\section{Tổng quan về mỏ cận biên}

Khái niệm mỏ cận biên thường gắn liền với các yếu tố chính là tính kinh tế, sản lượng khai thác và trữ lượng khai thác. Trong đó, tính kinh tế là yếu tố quyết định một mỏ dầu khí là mỏ cận biên hay không. Hiện nay, trên thế giới có rất nhiều

\section{*Tác giả liên hệ}

E - mail: nguyenvanthinh@humg.edu.vn

DOI: 10.46326/JMES.2021.62(3a).08 cách phân loại, xác định các mỏ (phát hiện dầu khí) là "có tính thương mại", "không thương mại" hoặc "cận biên", nhưng phổ biến nhất trong cách xác định là có sự kết hợp xem xét đến các yếu tố kinh tế, kỹ thuật, chính trị và tổng hòa lại là tính kinh tế của việc phát triển khai thác mỏ/phát hiện dầu khí đó. Khi nói tới mỏ cận biên (marginal field) là thường gắn liền với mỏ nhỏ. Hiện tại, có nhiều khái niệm, cách hiểu khác nhau về mỏ cận biên và thường phụ thuộc vào công nghệ áp dụng, 
các yếu tố về thương mại và kỹ thuật như: đặc tính của vỉa, cơ sở hạ tầng, chi phí phát triển,... Tùy vào tình hình, chính sách phát triển khai thác, mỗi quốc gia có một khái niệm, định nghĩa riêng về mỏ cận biên. Indonesia, Ecuador, các nước Bắc Mỹ và một số chuyên gia trong lĩnh vực dầu khí trên thế giới đưa ra định nghĩa mỏ cận biên dựa vào tính kinh tế, sản lượng khai thác của mỏ. Theo công trình nghiên cứu của tác giả Widjajono Partowidagdo (Partowidagdo, 1996), mỏ cận biên là một mỏ với các điều kiện tài chính hiện tại, có tỷ suất lợi tức nhỏ hơn tỷ suất thu lợi tối thiểu chấp nhận được. Nếu không có một vài khuyến khích cần thiết, những mỏ này sẽ không có hiệu quả kinh tế và không thể phát triển, khai thác. Theo định nghĩa mỏ cận biên trong hợp đồng của Indonesia, mỏ cận biên là mỏ đầu tiên trong phạm vi diện tích hợp đồng được đề nghị phát triển bởi nhà thầu, sản lượng khai thác bình quân của dự án trong 02 năm đầu tiên (24 tháng) không vượt quá 10 nghìn thùng/ngày (Lubiantara, 2005a, 2005b). Theo quan điểm của tác giả Stig Svalheim (Svalheim, 2004) đưa ra khái niệm mỏ cận biên là mỏ không thể khai thác và đem lại doanh thu thuần để phát triển mỏ ở một thời gian nhất định và cần phải có sự thay đổi về kỹ thuật hoặc điều kiện tài chính thì mỏ đó mới có thể có tính thương mại. Theo Sagex Petroleum AS (Sagex Petroleum AS, 2005), mỏ cận biên là một phát hiện hoặc mỏ đang được khai thác mà với những điều kiện hiện tại sẽ không mang lại lợi ích kinh tế để phát triển hoặc tiếp tục khai thác. Theo tác giả Benny Lubiantara (Lubiantara, 2005a, 2005b), mỏ cận biên là một mỏ dầu nằm trong phạm vi lô khai thác không đem lại lợi ích kinh tế để phát triển dưới các điều khoản Hợp đồng chia sản phẩm (PSC) và điều kiện hiện tại. Ngoài các định nghĩa về mỏ cận biên từ các nghiên cứu khác nhau, xét trên góc độ quốc gia, mỗi nước cũng có những cách hiểu khác nhau về mỏ cận biên, cụ thể như sau: ở Ecuador, các mỏ cận biên là những mỏ có tính kinh tế kém hoặc những mỏ được ưu tiên hoạt động và tổng sản lượng của các mỏ này nhỏ hơn $1 \%$ tổng sản lượng quốc gia (Deloitte, 2011). Bắc Mỹ không áp dụng khái niệm mỏ cận biên mà đưa ra định nghĩa giếng cận biên dựa vào sản lượng khai thác hàng ngày của giếng. Một giếng dầu được coi là giếng cận biên nếu khai thác không quá 10 thùng/ngày và một giếng khí thiên nhiên được coi là giếng cận biên nếu khai thác ít hơn 50 Mcf/ngày (Warlick, 2007). Một số nước khác như Malaysia, Hà Lan và Anh lại đưa ra khái niệm mỏ cận biên dựa vào trữ lượng của mỏ. Ở Việt Nam, trong nghiên cứu của tác giả Tăng Văn Đồng (Tăng Văn Đồng và nnk, 2017) cho rằng mỏ cận biên là mỏ có các đặc điểm như: mỏ có quy mô trữ lượng nhỏ, nằm ở khu vực nước sâu xa bờ; các phát hiện dầu khí nhưng không được thẩm lượng hoặc phát triển trong thời gian tối thiểu 10 năm; mỏ đã dừng khai thác ít nhất 1 năm vì lý do kinh tế. Như vậy, mỗi quốc gia, mỗi tổ chức đều có cách nhìn và định nghĩa khác nhau về mỏ nhỏ/mỏ cận biên, trong đó, các yếu tố dẫn đến việc xác định mỏ cận biên thì rất nhiều như: trữ lượng, sản lượng, điều kiện khai thác, điều kiện cơ sở hạ tầng, giá dầu/khí, tính hiệu quả cho nhà đầu tư nếu phát triển khai thác mỏ đó,... nhưng điểm phổ biến nhất vẫn là tính kinh tế của việc phát triển khai thác mỏ.

\section{Tình trạng thiết bị hiện có tại Bể Cửu Long}

Dựa trên kinh nghiệm phát triển các mỏ có trữ lượng vừa và nhỏ cho thấy phương án kết nối về các trung tâm xử lý hiện hữu sẽ cho hiệu quả kinh tế cao (Tăng Văn Đồng và nnk., 2017a; 2017b; Nguyễn Vũ Trường Sơn và nnk., 2017; Vũ Minh Đức, 2015; Tống Cảnh Sơn, Lê Đình Hòe, 2015; Phùng Đình Thực và nnk., 2002). Các nghiên cứu tập trung vào đánh giá về công suất dư, sản lượng khai thác và khả năng cải hoán thiết bị hiện có để phục vụ cho công tác kết nối các mỏ mới. Các lô có hệ thống thiết bị xử lý vận hành khai thác bao gồm: Lô 15.1 - Cửu Long JOC, Lô 16.1 - Hoàng Long Hoàn Vũ JOC, Lô 01 \& 02 - PCVL, Lô 15.2 - JVPC, Lô 09.1 - VSP và Lô 01 \& 02/97 do Lam Sơn JOC điều hành. Các thống kê về công suất thiết kế của hệ thống thiết bị hiện hữu kết hợp với sản lượng khai thác dự tính của toàn bộ cụm xử lý bể Cửu Long (Hình 1,2$)$ cho thấy công suất xử lý sản phẩm khai thác hiện tại ở các mỏ của bể Cửu Long chưa sử dụng hết so với công suất thiết kế. Đây là điều kiện khả thi cho việc xem xét khả năng kết nối thêm các cấu tạo tiềm năng lân cận. Tiêu biểu trong đó, hai yếu tố chính là công suất xử lý dầu, khí và các yếu tố còn lại được thể hiện trên các Hình 1 và 2 . 


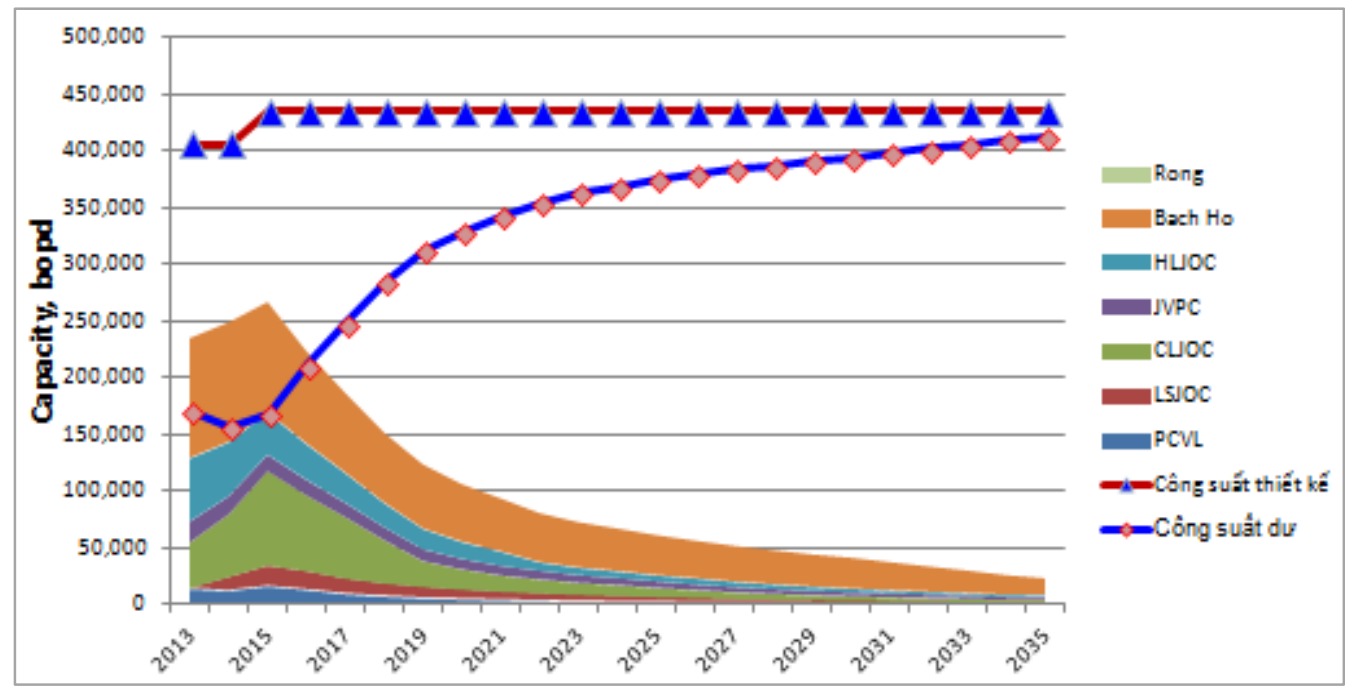

Hình 1. Biểu đồ công suất xử lý dầu của toàn bộ cụm xử lý bể Cưu Long

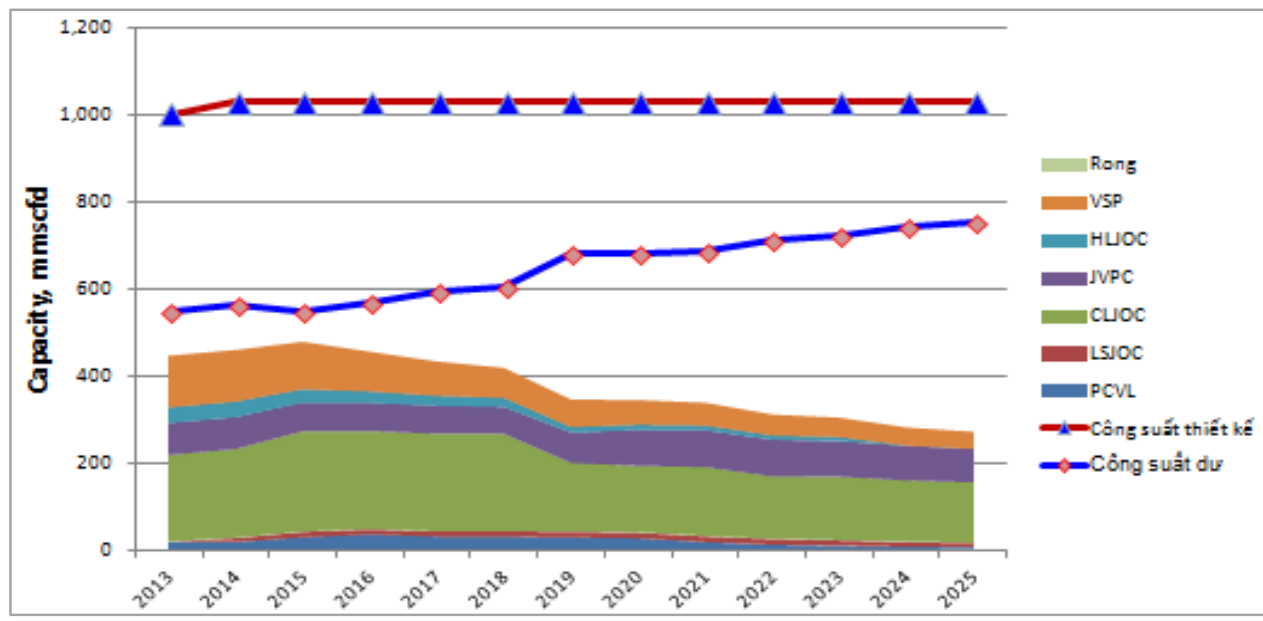

Hình 2. Biểu đồ công suất xử lý khí của toàn bộ cụm xử lý bể Cửu Long.

\section{1. Đánh giá khả năng kết nối các trữ lượng tiềm năng}

Dựa trên kết quả đánh giá tổng thể về cơ sở hạ tầng hiện tại và tương lai gần, dự báo về sản lượng khai thác cũng như ước tính công suất xử lý dư của toàn bể Cửu Long hay từng cụm trung tâm xử lý chính, việc đưa các cấu tạo tiềm năng vào phát triển bằng cách kết nối về hệ thống thiết bị, trung tâm xử lý là hoàn toàn phù hợp và được đánh giá là phương án khả thi về kĩ thuật và triển vọng về hiệu quả kinh tế. Trên cơ sở đó, sẽ có 6 trung tâm xử lý chính ở bể Cửu Long được cho là phù hợp với phương án kết nối bao gồm: CLJOC
(FPSO-TBVN và Sư Tử Vàng CPP), JVPC (Rạng Đông CPC), LSJOC (FPSO PTSC-Lam Sơn), Bạch Hổ $\mathrm{CPP}$, Cự Rồng và HLJOC (FPSO Bumi Armada). Việc kết nối các cấu tạo cần phải dựa trên các tiêu chí ưu tiên như:

- Ưu tiên cấu tạo tại lô đang có hệ thống thiết bị đủ công suất kết nối thêm;

- Ưu tiên xác suất thành công cấu tạo cao và ưu tiên mỏ dầu trước;

- Ưu tiên cấu tạo có trữ lượng thu hồi trên 10 triệu thùng;

- Giới hạn khoảng cách đến trung tâm xử lý hiện hữu là $30 \mathrm{~km}$ (giới hạn này được dựa trên kết 
quả đánh giá nghiên cứu về thủy lực dòng chảy nhiều pha).

\subsubsection{Phương án kết nối về STV-CPP (CLJOC)}

Đánh giá cho thấy, công suất nén dư của STVCPP sẽ thiếu hụt, nếu đưa Lạc Đà Vàng, Lạc Đà Xám, Beta và Spinel kết nối vào giàn STV CPP cần cân nhắc đến các yếu tố như sau:

- Nâng cấp hệ thống máy nén của giàn STVCPP $160 \div 250$ triệu bộ khối khí/ngày để đáp ứng công suất nén. Trong trường hợp này cần đưa thời điểm khai thác dòng dầu đầu tiên (FO)dự kiến của 2 cấu tạo Lead $B$ và Lead $C$ lên sớm để tận dụng công suất dư của STV-CPP.

- Nâng cấp hệ thống máy nén của STV-CPP từ 160 triệu bộ khối khí/ngày lên 200 triệu bộ khối khí/ngày và đẩy lùi thời điểm $\mathrm{FO}$ dự kiến của Lạc Đà Vàng, Beta và Spinel (Lô 01\&02/10). Sơ đồ hệ thống thiết bị cụm mỏ trong phương án kết nối này được trình bày sơ bộ trong Hình 3 . Các phương án kết nối chi tiết được thể hiện trong Bảng 1.

\subsubsection{Phương án kết nối về cụm mỏ Rạng Đông (JVPC)}

Các cấu tạo tiềm năng dự kiến kết nối về cụm mỏ Rạng Đông do JVPC điều hành đã được đánh giá và trình bày trong Bảng 2 . Khi đưa các cấu tạo tiềm năng phát triển kết nối vào JVPC cần lắp đặt thêm 1 hệ thống xử lý nước khai thác. Cải hoán, nâng công suất của máy nén trên giàn $\mathrm{CPC}$ để có đủ khả năng cấp khí gas lift cho các cấu tạo kết nối về.

\subsubsection{Phương án kết nối về LSJOC}

Do chỉ có cấu tạo tiềm năng Kình ngư vàng (KNV)-Nam trong lô hợp đồng 01\&02/10 (dự tính 17,3 triệu thùng dầu thu hồi) có khả năng kết nối về trung tâm xử lý của LSJOC - Tàu FPSO PTSC Lam Sơn, nên đề xuất những điểm sau:

- Cải hoán tàu FPSO phù hợp trong trường hợp đưa cấu tạo KNV-Nam kết nối về LSJOC;

- Cân nhắc khả năng phát triển độc lập của KNV-Nam do tại FPSO hạn chế công suất xử lý nước, công suất máy nén khí và bơm ép nước.

\subsubsection{Phương án kết nối về Bạch Hổ CPP}

Trong trường hợp kết nối các cấu tạo tiềm năng vào giàn công nghệ trung tâm thì cần phải xem xét khả năng lắp đặt thêm đường ống kết nối và cải hoán các hệ thống thiết bị tiếp nhận. Các phương án kết nối được trình bày chi tiết trong Bảng 3.

\subsubsection{Phương án kết nối về Rồng $C P P$}

Đánh giá công suất của cụm Rồng CPP cho thấy: Công suất dư của Rồng CPP từ năm 2021 sẽ không đủ để xử lý phần sản phẩm của các cấu tạo dự kiến kết nối. Đề xuất phương án cải hoán để nâng công suất xử lý lỏng tại RP1; công suất tối đa của giàn nén DCP 1,4 triệu mét khối khí/ngày là không đủ khi đưa các cấu tạo kết nối vào Rồng. Các phương án kết nối được trình bày chi tiết trong Bảng 4.

\subsubsection{Phương án kết nối về HLJOC}

Đánh giá phương án phương án kết nối chi tiết được trình bày trong Bảng 5 . Trường hợp công suất xử lý khí của HLJOC không đủ để xử lý thì cần phải thay đổi cấu tạo. Mặt khác, do FPSO Armada TGT 1 không có riser đường ống kết nối dự phòng. Để sử dụng công suất xử lý tàu FPSO Armada TGT 1 cần lên phương án kết nối các cấu tạo khác vào giàn TGT H1, TGT H4, Hải Sư Trắng hoặc Hải Sư Đen (Hình 4).

\subsection{Công nghệ khai thác và vận chuyển sản phẩm của các mỏ bể Cửu Long}

Với những thuận lợi như vị trí địa lý gần bờ, mực nước biển nông $(35 \div 60 \mathrm{~m})$, nên hệ thống thiết bị khai thác của các mỏ tại bể Cửu Long đều theo mô hình truyền thống: sử dụng giàn đầu giếng cố định không người để khai thác, xử lý sơ bộ và thu gom dầu khí; sản phẩm sau đó được đẩy theo đường ống nội mỏ về khu xử lý trung tâm CPP hoặc tàu FPSO tiếp tục xử lý đạt yêu cầu dầu khí thành phẩm để lưu trữ và xuất bán (Hình 5 ).

Giàn đầu giếng cố định không người (WHP): được thiết kế tối giản về diện tích, kết cấu cũng như thiết bị trên giàn. Tùy theo thiết kế, khối thượng tầng sẽ chỉ nặng $500 \div 1.500$ tấn, khối chân đế nặng $1.500 \div 2.000$ tấn. Hệ thống thiết bị cơ bản trên giàn bao gồm: đầu giếng, hệ thống thu gom, bình tách thử, hệ thống phóng thoi, bơm tăng áp, các hệ thống phụ trợ như hóa phẩm, điều khiển, thiết bi an toàn.

Giàn xử lý công nghệ trung tâm (CPP): được thiết kế để thu gom, xử lý dầu khí từ các đầu giếng của giàn và từ các giàn vệ tinh lân cận. Thông thường, để cất giữ dầu thành phẩm, giàn được kết 


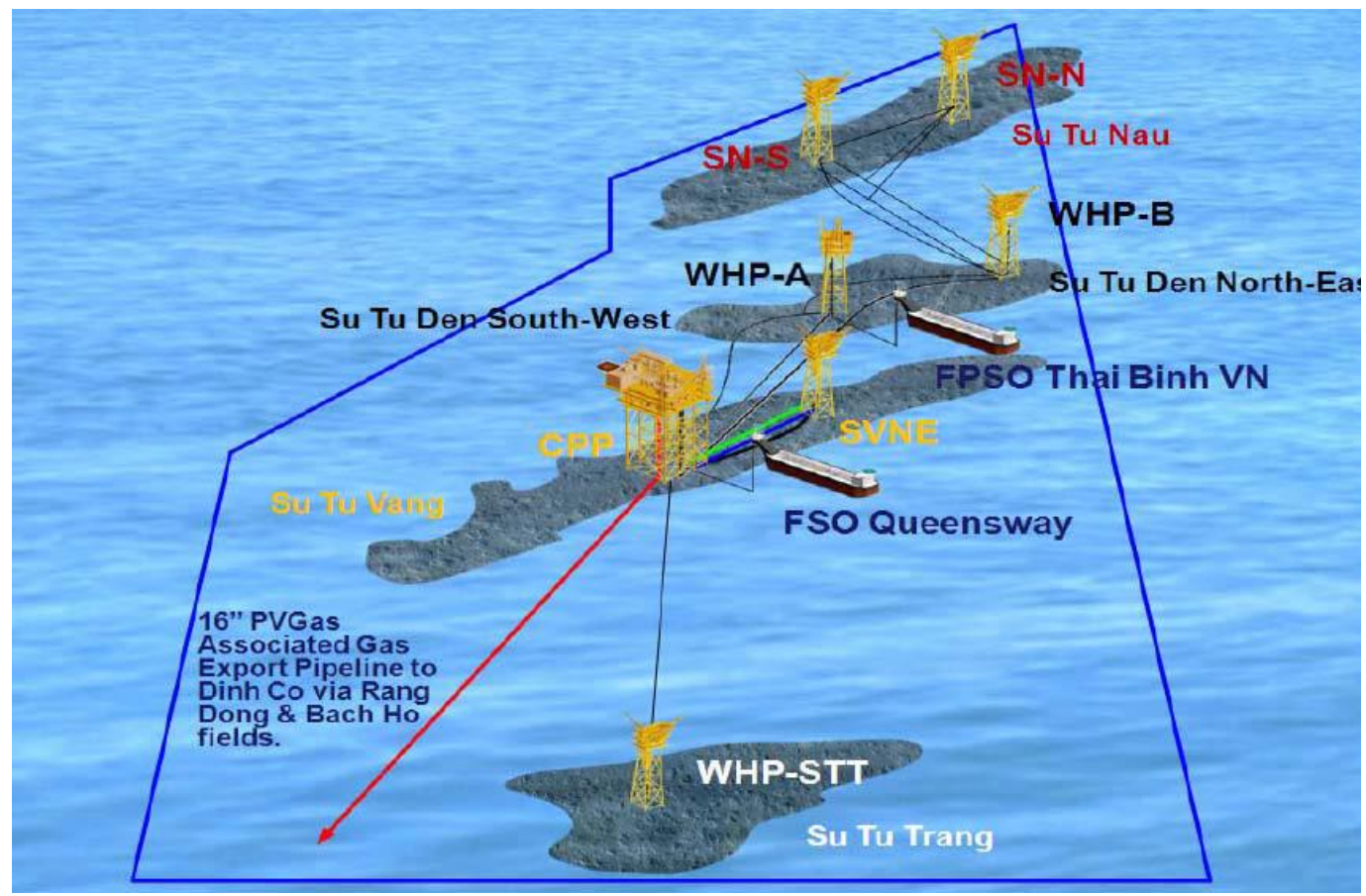

Hình 3. Sơ đồ hệ thống thiết bị cụm mỏ trong phương án STV-CPP.

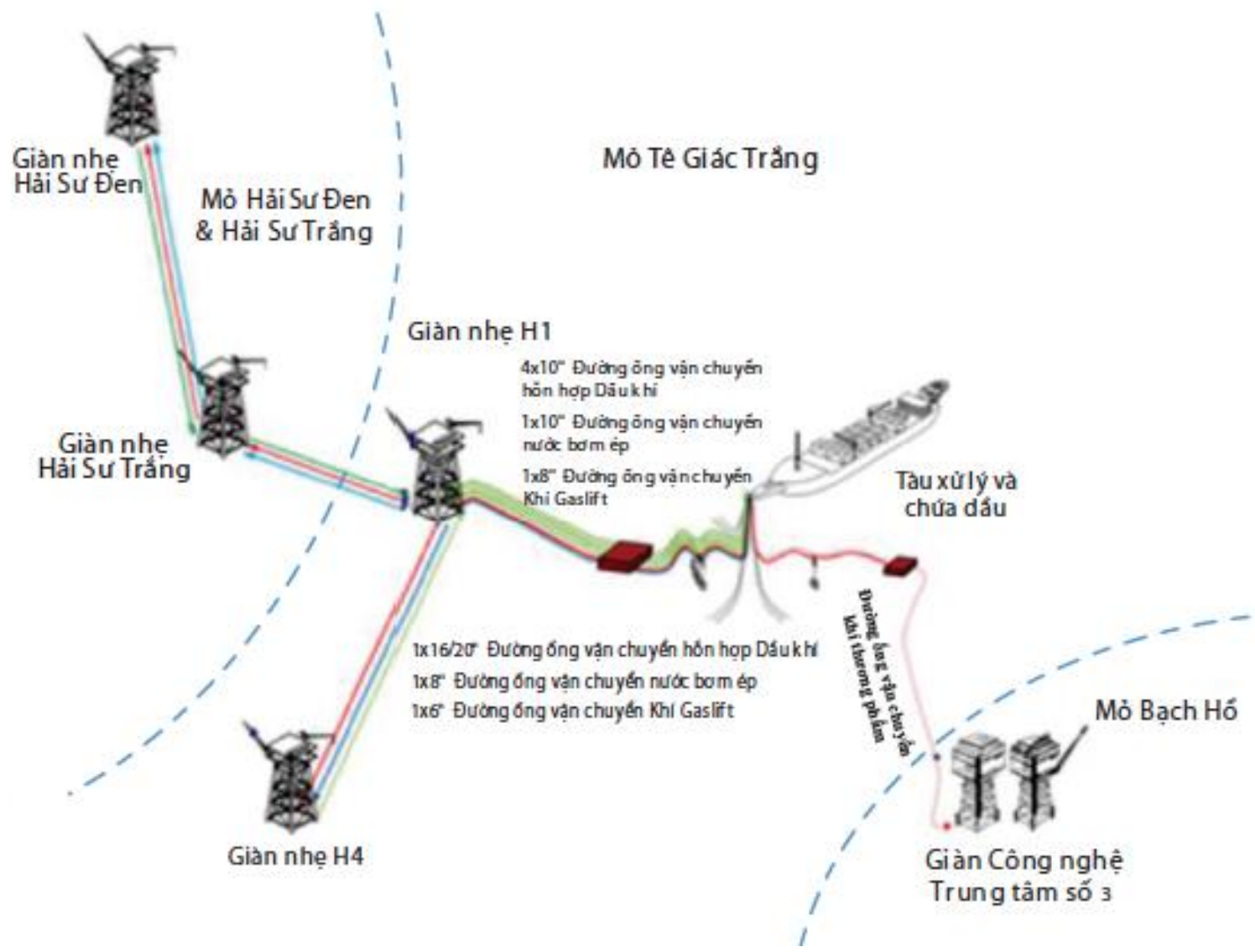

Hình 4. Sơ đồ cụm mỏ trong phương án HLJOC. 


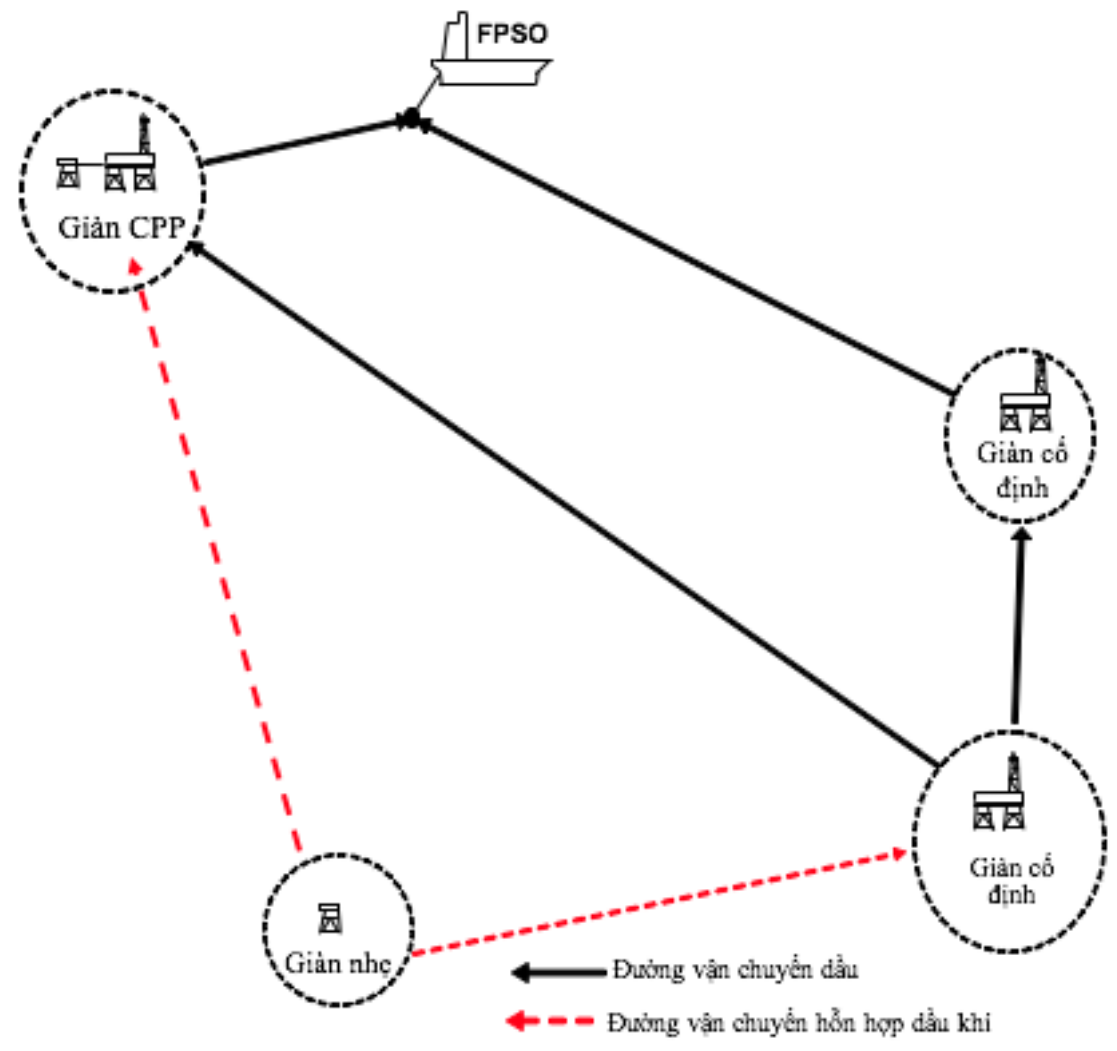

Hình 5. So đồ vận chuyển sản phẩm đặc trung ở bể Cửu Long.

Bảng 1. Các cấu tạo tiềm năng dự kiến kết nối về CLJOC.

\begin{tabular}{|c|c|c|c|c|c|c|c|c|c|c|c|c|}
\hline \multirow{3}{*}{$\begin{array}{l}\text { Trung tâm } \\
\text { kết nối }\end{array}$} & \multirow{3}{*}{ Cấu tạo } & \multirow{3}{*}{$\begin{array}{l}\text { Lô hợp } \\
\text { đồng }\end{array}$} & \multicolumn{2}{|c|}{$\begin{array}{c}\text { Trữ lượng tại } \\
\text { chỗ }\end{array}$} & \multicolumn{2}{|c|}{ Trữ lượng } & \multirow{2}{*}{\multicolumn{2}{|c|}{ Số giếng }} & \multirow{3}{*}{$\begin{array}{c}\text { Xác suất } \\
\text { thành } \\
\text { công }\end{array}$} & \multirow{3}{*}{ Loại } & \multirow{3}{*}{$\begin{array}{l}\text { Điểm } \\
\text { kết nối }\end{array}$} & \multirow{3}{*}{$\begin{array}{c}\text { Khoảng } \\
\text { cách } \\
(\mathrm{km})\end{array}$} \\
\hline & & & Dầu & Khí & Dầu & Khí & & & & & & \\
\hline & & & $\begin{array}{l}\text { Triệu } \\
\text { thùng }\end{array}$ & $\begin{array}{l}\text { Tỷ bộ } \\
\text { khối }\end{array}$ & $\begin{array}{l}\text { Triệu } \\
\text { thùng }\end{array}$ & $\begin{array}{l}\text { Tỷ bộ } \\
\text { khối }\end{array}$ & $\begin{array}{l}\text { Khai } \\
\text { thác }\end{array}$ & $\begin{array}{l}\text { Bơm } \\
\text { ép }\end{array}$ & & & & \\
\hline \multirow{9}{*}{$\begin{array}{c}\text { STV-CPP } \\
\text { TBVN } \\
\text { FPSO } \\
\text { (CLJOC) }\end{array}$} & $\begin{array}{l}\text { Su Tu } \\
\text { Do }\end{array}$ & 15.1 & 212,96 & & 33,49 & & 12 & 4 & 0,26 & 1 & $\begin{array}{l}\text { TBVN- } \\
\text { FPSO }\end{array}$ & 7 \\
\hline & \begin{tabular}{|c|} 
Su Tu \\
Trang \\
NE \\
\end{tabular} & 15.1 & & 661,92 & & 331,00 & 6 & & 0,26 & 2 & $\begin{array}{l}\text { STT } \\
\text { CPP }\end{array}$ & 10 \\
\hline & $\begin{array}{c}\text { Lạc Đà } \\
\text { Vàng }\end{array}$ & $15-1 / 05$ & 199,47 & & 29,35 & & 8 & 4 & 1 & 3 & $\begin{array}{l}\text { STV- } \\
\text { CPP }\end{array}$ & 19 \\
\hline & \begin{tabular}{|c|} 
Lạc Đà \\
Xám \\
\end{tabular} & $15-1 / 05$ & 102,08 & & 14,44 & & 4 & 2 & 0,28 & 4 & $\begin{array}{c}\text { Lạc Đà } \\
\text { Vàng }\end{array}$ & 8 \\
\hline & $\begin{array}{c}\text { Hổ } \\
\text { Vàng }\end{array}$ & $01 \& 02 / 10$ & 67,9 & & 21 & & 3 & 1 & 0,21 & 5 & \begin{tabular}{|l|} 
STN- \\
North \\
\end{tabular} & 20 \\
\hline & Beta & $01 \& 02 / 10$ & 72,746 & & 13,87 & & 9 & 2 & 0,19 & 6 & $\begin{array}{l}\text { STN- } \\
\text { North }\end{array}$ & 20 \\
\hline & Spinel & $01 \& 02 / 10$ & 86,59 & & 15,53 & & 7 & 2 & 0,14 & 7 & $\begin{array}{l}\text { Beta- } \\
\text { STN- } \\
\text { North }\end{array}$ & $5-20$ \\
\hline & Lead B & $15-1 / 05$ & 305,32 & & 46,71 & & 13 & 4 & 0,083 & 8 & $\begin{array}{l}\text { STV- } \\
\text { CPP }\end{array}$ & 13,5 \\
\hline & Lead C & $15-1 / 05$ & 103,75 & & 14,93 & & 5 & 2 & 0,07 & 9 & Lead B & 6 \\
\hline
\end{tabular}


Bảng 2. Các cấu tạo tiềm năng dự kiến kết nối về JVPC.

\begin{tabular}{|c|c|c|c|c|c|c|c|c|c|c|c|c|}
\hline \multirow{3}{*}{$\begin{array}{c}\text { Trung } \\
\text { tâm kết } \\
\text { nối }\end{array}$} & \multirow{3}{*}{ Cấu tạ } & \multirow{3}{*}{$\begin{array}{l}\text { Lô hợp } \\
\text { đồng }\end{array}$} & \multicolumn{2}{|c|}{$\begin{array}{l}\text { Trữ lượng tại } \\
\text { chỗ }\end{array}$} & \multicolumn{2}{|c|}{ Trữ lượng } & \multirow{2}{*}{\multicolumn{2}{|c|}{ Số giếng }} & \multirow{3}{*}{$\begin{array}{c}\text { Xác } \\
\text { suất } \\
\text { thành } \\
\text { công }\end{array}$} & \multirow{3}{*}{ Loại } & \multirow{3}{*}{$\begin{array}{c}\text { Điểm } \\
\text { kết nốic }\end{array}$} & \multirow{3}{*}{$\begin{array}{l}\text { Khoảng } \\
\text { cách (km }\end{array}$} \\
\hline & & & \multirow{2}{*}{$\begin{array}{c}\text { Dầu } \\
\text { Triệu } \\
\text { thùng }\end{array}$} & \multirow{2}{*}{$\begin{array}{c}\text { Khí } \\
\text { Tỷ bộ } \\
\text { khối }\end{array}$} & \multirow{2}{*}{$\begin{array}{c}\text { Dầu } \\
\text { Triệu } \\
\text { thùng }\end{array}$} & \multirow{2}{*}{$\begin{array}{l}\text { Khí } \\
\text { Tỷ bố } \\
\text { khối }\end{array}$} & & & & & & \\
\hline & & & & & & & Khai thác & Bơm ép & & & & \\
\hline \multirow{9}{*}{$\begin{array}{c}\text { Rang } \\
\text { Dong CPd }\end{array}$} & NIA & 15.2 & 33,6 & & 5,64 & & 3 & 1 & 0,33 & 1 & JVPC & 4 \\
\hline & $\begin{array}{l}\text { Rang } \\
\text { Dong }\end{array}$ & 15.2 & 59,31 & & 8,4 & & 5 & 1 & 0,3 & 2 & JVPC & 13 \\
\hline & $\mathrm{D}$ & 15.2 Open & 89,61 & & 13,46 & & 5 & 4 & 0,13 & 3 & $\begin{array}{l}\text { RD- } \\
\text { JVPC }\end{array}$ & 12 \\
\hline & $\begin{array}{c}\text { Kình } \\
\text { Ngư } \\
\text { trắng }\end{array}$ & $09-2 / 09$ & 100,95 & & 9,91 & & 9 & 2 & 1 & 4 & JVPC & 18 \\
\hline & \begin{tabular}{|c|} 
Kình \\
Ngư \\
trắng \\
(Gas) \\
\end{tabular} & $09-2 / 09$ & & 147,73 & & 20,76 & 4 & & 1 & 4 & JVPC & 18 \\
\hline & $\begin{array}{l}\text { KNT } \\
\text { Nam }\end{array}$ & $09-2 / 09$ & 71,95 & & 11,17 & & 6 & 4 & 0,21 & 5 & KNT & 5 \\
\hline & Opal & $01 \& 02 / 10$ & 91,7 & & 18,41 & & 7 & 2 & 0,19 & 6 & KNT & 20 \\
\hline & COD & $09-2 / 09$ & 62,64 & & 8,02 & & 5 & & 0,11 & 7 & KNT & 6 \\
\hline & Lead A & $09-2 / 09$ & 98,26 & & 14,84 & & 5 & 3 & 0,08 & 8 & COD & 4 \\
\hline
\end{tabular}

Bảng 3. Các cấu tạo tiềm năng dụ kiến kết nối về Bạch Hổ CPP.

\begin{tabular}{|c|c|c|c|c|c|c|c|c|c|c|c|c|}
\hline \multirow{3}{*}{$\begin{array}{l}\text { Trung } \\
\text { tâm } \\
\text { kết nối }\end{array}$} & \multirow{3}{*}{ Cấu tạo } & \multirow{3}{*}{$\begin{array}{l}\text { Lô hợp } \\
\text { đồng }\end{array}$} & \multicolumn{2}{|c|}{\begin{tabular}{|c}
$\begin{array}{c}\text { Trữ lượng tại } \\
\text { chỗ }\end{array}$ \\
\end{tabular}} & \multicolumn{2}{|c|}{ Trũ̃ lượng } & \multirow{2}{*}{\multicolumn{2}{|c|}{ Số giếng }} & \multirow{3}{*}{$\begin{array}{l}\text { Xác } \\
\text { suất } \\
\text { thành } \\
\text { công }\end{array}$} & \multirow{3}{*}{ Loại } & \multirow{3}{*}{$\begin{array}{l}\text { Điểm kết } \\
\text { nối }\end{array}$} & \multirow{3}{*}{$\begin{array}{l}\text { Khoảng } \\
\text { cách } \\
(\mathrm{km})\end{array}$} \\
\hline & & & Dầu & Khí & Dầu & Khí & & & & & & \\
\hline & & & $\begin{array}{l}\text { Triệu } \\
\text { thùng }\end{array}$ & \begin{tabular}{|} 
Tỷ \\
bộ \\
khối \\
\end{tabular} & $\begin{array}{l}\text { Triệu } \\
\text { thùng }\end{array}$ & $\begin{array}{r}\text { Tỷ } \\
\text { bộ } \\
\text { khối }\end{array}$ & Khai thác & Bơm ép & & & & \\
\hline \multirow{3}{*}{$\begin{array}{c}\text { Bạch } \\
\text { Hổ } \\
\text { CPP }\end{array}$} & Alpha & $09-2 / 10$ & 184,82 & & 37,78 & & 19 & 3 & 0,25 & 1 & Bạch Hổ & 16 \\
\hline & Карра & $09-2 / 10$ & & & & & & & 0,229 & 2 & Alpha & 3 \\
\hline & Omega & $09-2 / 10$ & 37,1 & & 5,11 & & 4 & & 0,145 & 3 & Bạch Hổ & 12 \\
\hline
\end{tabular}


Bảng 4. Các cấu tạo tiềm năng dự kiến kết nối về Rồng CPP.

\begin{tabular}{|c|c|c|c|c|c|c|c|c|c|c|c|c|}
\hline \multirow{3}{*}{$\begin{array}{c}\text { Trung } \\
\text { tâm kết } \\
\text { nối }\end{array}$} & \multirow{3}{*}{ Cấu tạo } & \multirow{3}{*}{$\begin{array}{l}\text { Lô hợp } \\
\text { đồng }\end{array}$} & \multicolumn{2}{|c|}{$\begin{array}{c}\text { Trữ lượng tại } \\
\text { chỗ }\end{array}$} & \multicolumn{2}{|c|}{ Trữ lượng } & \multirow{2}{*}{\multicolumn{2}{|c|}{ Số giếng }} & \multirow{3}{*}{$\begin{array}{c}\text { Xác suất } \\
\text { thành } \\
\text { công }\end{array}$} & \multirow{3}{*}{ Loại } & \multirow{3}{*}{ Điểm } & \multirow{3}{*}{$\begin{array}{c}\text { Khoảng } \\
\text { cách } \\
(\mathrm{km})\end{array}$} \\
\hline & & & Dầu & Khí & Dầu & Khí & & & & & & \\
\hline & & & $\begin{array}{l}\text { Triệu } \\
\text { thùng }\end{array}$ & $\begin{array}{l}\text { Tỷ bộ } \\
\text { khối }\end{array}$ & $\begin{array}{l}\text { Triệu } \\
\text { thùng }\end{array}$ & $\begin{array}{l}\text { Tỷ bộ } \\
\text { khối }\end{array}$ & Khai thác & Bơm ép & & & & \\
\hline \multirow{5}{*}{$\begin{array}{l}\text { Rong } \\
\text { CPP }\end{array}$} & Vải Thiều & 17 Open & 180,9 & & 30,15 & & 14 & 5 & 0,35 & 1 & Rồng & 19 \\
\hline & DM Nam & 09.03 & 83,5 & & 8,91 & & 4 & & 0,33 & 2 & Rồng & 5,5 \\
\hline & $\begin{array}{c}\text { Đồi Mồi } \\
\text { DN }\end{array}$ & 09.03 & 77,09 & & 11,45 & & 3 & 1 & 0,22 & 3 & Rồng & 7 \\
\hline & Dơi Xám & $16-2$ & 120,61 & & 19,72 & & 7 & 2 & 0,20 & 4 & Rồng & 16 \\
\hline & $\begin{array}{c}\text { Bẫy Địa } \\
\text { Tầng DM }\end{array}$ & 09.03 & 24,41 & 147,73 & 2,29 & 20,76 & 3 & & 0,2 & 5 & Rồng & 6 \\
\hline
\end{tabular}

Bảng 5. Các cấu tạo tiềm năng dự kiến kết nối về HLJOC.

\begin{tabular}{|c|c|c|c|c|c|c|c|c|c|c|c|c|}
\hline \multirow{3}{*}{$\begin{array}{l}\text { Trung } \\
\text { tâm } \\
\text { kết nối }\end{array}$} & \multirow{3}{*}{$\begin{array}{l}\text { Cấu } \\
\text { tạo }\end{array}$} & \multirow{3}{*}{$\begin{array}{c}\text { Lô } \\
\text { hợp } \\
\text { đồng }\end{array}$} & \multicolumn{2}{|c|}{\begin{tabular}{|c} 
Trữ lượng tại \\
chỗ
\end{tabular}} & \multicolumn{2}{|c|}{ Trữ lượng } & \multirow{2}{*}{\multicolumn{2}{|c|}{ Số giếng }} & \multirow{3}{*}{$\begin{array}{c}\text { Xác } \\
\text { suất } \\
\text { thành } \\
\text { công }\end{array}$} & \multirow{3}{*}{ Loại } & \multirow{3}{*}{$\begin{array}{c}\text { Điểm kết } \\
\text { nối }\end{array}$} & \multirow{3}{*}{$\begin{array}{c}\text { Khoảng } \\
\text { cách } \\
(\mathrm{km})\end{array}$} \\
\hline & & & \multirow{2}{*}{\begin{tabular}{|c|} 
Dầu \\
Triệu \\
thùng \\
\end{tabular}} & \multirow{2}{*}{\begin{tabular}{|c|} 
Khí \\
$\begin{array}{c}\text { Tỷ bộ } \\
\text { khối }\end{array}$ \\
\end{tabular}} & \multirow{2}{*}{\begin{tabular}{|c|} 
Dầu \\
Triệu \\
thùng \\
\end{tabular}} & \multirow{2}{*}{\begin{tabular}{|c|} 
Khí \\
Tỷ bộ \\
khối
\end{tabular}} & & & & & & \\
\hline & & & & & & & $\begin{array}{l}\text { Khai } \\
\text { thác }\end{array}$ & Bơm ép & & & & \\
\hline \multirow{6}{*}{ HLJOC } & H5 & $\begin{array}{l}15.2 \\
\text { Open }\end{array}$ & & & & & & & 1 & 1 & JTGT-H4 & 12 \\
\hline & HSV-C & $\begin{array}{c}15.2 \\
\text { Open }\end{array}$ & 125 & & 19,43 & & 15 & & 0,25 & 2 & TGT-H4 & 24 \\
\hline & HSV-N & $\begin{array}{c}15.2 \\
\text { Open }\end{array}$ & 69,5 & & 11,56 & & 4 & 1 & 0,25 & 3 & TGT-H4 & 4 \\
\hline & HSV-S & $\begin{array}{l}15.2 \\
\text { Open }\end{array}$ & 47,77 & & 7,73 & & 2 & 2 & 0,25 & 4 & TGT-H4 & 4 \\
\hline & $\begin{array}{c}\text { Tê } \\
\text { Giác } \\
\text { Vàng }\end{array}$ & $\begin{array}{c}15.2 \\
\text { Open }\end{array}$ & 243,5 & & 49,2 & & 19 & 4 & 0,23 & 5 & TGT-H4 & 12 \\
\hline & TGD & $\begin{array}{c}15.2 \\
\text { Open }\end{array}$ & & 571,9 & & 283,67 & 5 & & 0,16 & 6 & TGT-H4 & 20 \\
\hline
\end{tabular}

nối với tàu chứa dầu FSO. Với các đặc điểm trên, giàn xử lý trung tâm thường có kết cấu phức tạp và nặng hơn nhiều so với giàn không người, thông thường khối thượng tầng có thể nặng đến trên 10.000 tấn và khối chân đế có thể nặng từ $5.000 \div 8.000$ tấn. Hệ thống xử lý trên CPP rất phức tạp, bao gồm các công đoạn xử lý dầu, khí, nước khai thác, nước bơm ép, các hệ thống tiện ích/phụ trợ và các hệ thống an toàn, phòng chống cháy nổ khác. Công đoạn xử lý dầu thường bao gồm các cấp bình tách theo áp suất từ cao đến thấp. Nước tách ra được đưa qua hệ thống xử lý nước đến tiêu chuẩn cho phép trước khi thải ra môi trường (dầu trong nước thải nhỏ hơn 40 ppm). Khí được xử lý làm mát, nén tăng áp rồi qua hệ thống làm khô và sau đó được sử dụng với các mục đích làm khí nâng hoặc xuất bán. Một phần khí sẽ được sử dụng làm khí nguyên liệu phục vụ cho hoạt động vận hành trên giàn. 
Kho chứa, xử lý nổi (FPSO): là mô hình khai thác, xử lý phổ biến nhất trong hoạt động dầu khí tại bể Cửu Long với những lợi ích như: khả năng cất chứa dầu lớn, tính linh động cao, có thể cải hoán từ tàu dầu cũ nên giảm chi phí đầu tư và sau khi kết thúc dự án cũng có thể cải hoán để tiếp tục sử dụng cho dự án mới, ngoài ra việc thi công lắp đặt cũng dễ dàng hơn. Sức chứa của FPSO thông thường từ $500.000 \div 1000.000$ thùng. Hệ thống xử lý của tàu FPSO thường được đặt trên topside của tàu, bao gồm hệ thống xử lý, khu nhà ở, sân bay... giống với giàn công nghệ trung tâm.

\subsection{Công nghệ tiềm năng cho phát triển các mỏ cận biên bể Cửu Long}

Giàn MOPU (Mobile offshore Production Unit): Loại giàn này được sử dụng cho các mỏ cận biên khai thác sớm. Trên khối thượng tầng MOPU được cải hoán để lắp đặt hệ thống xử lý dầu khí, hệ thống nhà ở, sân bay... như trên CPP hoặc FPSO. Mô hình khai thác sử dụng MOPU thường được thiết kế như sau: Wellhead Frame + MOPU (với hệ thông xử lý hoàn chỉnh) + FSO.

Wellhead Support Frame: sử dụng với giàn MOPU (Mobile offshore Production Unit) được thiết kế tối giản chỉ với hệ thống đầu giếng, sản phẩm từ các đầu giếng được chuyển trực tiếp lên trung tâm công nghệ tại MOPU để xử lý.

Giàn khai thác và xử lý kết cấu nhẹ: được thiết kế về cơ bản tương tự như giàn khai thác không người thông thường, tuy nhiên có thêm các module xử lý dầu khí. Hệ thống xử lý được thiết kế tối giản để giảm độ phức tạp trong công nghệ, qua đó giảm thiểu sự can thiệp của con người.

\section{3. Đảm bảo dòng chảy cho các phương án phát triển}

Đối với phương án kết nối về hệ thống thiết bị hiện hữu, cần phải tiến hành đánh giá công suất xử lý dư, tình trạng hiện tại của hệ thống thiết bị, khả năng hoán cải. Nội dung nghiên cứu dòng chảy cho các phương án phát triển đóng vai trò quan trọng trong quá trình thực hiện nghiên cứu quy hoạch tổng thể các mỏ bể Cửu Long. Mục đích nhằm xác định khả năng vận chuyển dòng chất lỏng tối đa, nhằm lựa chọn phương án phát triển an toàn và hiệu quả cho các mỏ cận biên. Kết quả nghiên cứu đã chỉ ra các điểm chính như sau:

- Kích thước đường ống tối thiểu lựa chọn 6 inch do chi phí xây dựng đường ống biển lớn;

- Kích thước đường ống lớn nhất 22 inch (để vận chuyển được 45.000 thùng dầu/ngày);

- Chiều dài tối đa không vượt quá 25 km (nếu vận chuyển dưới 30.000 thùng dầu/ngày), dưới $30 \mathrm{~km}$ nếu vận chuyển với lưu lượng trên 30.000 thùng dầu/ngày để đảm bảo nhiệt độ trong đường ống luôn trên nhiệt độ tạo sáp $5^{\circ} \mathrm{C}$;

Ngoài ra, trong quá trình hoạt động cần phải có bơm hóa phẩm PPD để giảm giá trị áp suất khởi động đường ống và áp suất khi khởi động lại hệ thống sau khi ngừng khai thác.

\section{Kết luận}

Giải pháp phát triển kết nối các mỏ nhỏ vào hệ thống thiết bị sẵn có ở lân cận đã được triển khai áp dụng và được khẳng định mức độ an toàn, đạt hiệu quả cao tại các mỏ Cá Ngừ Vàng, Nam Rồng Đồi Mồi và Hải Sư Đen, Hải Sư Trắng. Đây sẽ là hướng phát triển chính, mang tính chủ đạo đối với các mỏ nhỏ, cận biên ở bể Cửu Long cũng như tại thềm lục địa Việt Nam, nơi có các cụm thiết bị công nghệ đủ khả năng kết nối và xử lý sản phẩm dầu và khí. Cùng với đó, các tiêu chí ưu tiên được sử dụng nhằm đưa các cấu tạo tiềm năng dự kiến vào kết nối để tiến hành khai thác. Mỗi lô đưa vào đánh giá cần phải đảm bảo những nội dung chính như: thông tin cơ sở của lô, vị trí địa lý, thông tin về các tầng sản phẩm, số giếng khoan, trữ lượng tại chỗ, trữ lượng thu hồi; các phương án phát triển; sơ đồ phát triển và thiết bị (số giàn khai thác, trung tâm xử lý/tàu FPSO, hệ thống đường ống khai thác, bơm ép khí/nước). Việc lựa chọn giải pháp hiệu quả để kết nối các mỏ cận biên dựa trên cơ sở hạ tầng sẵn có của các mỏ hiện hữu trong khu vực lân cận để tiến hành thu gom, xử lý và vận chuyển sản phẩm là giải pháp hợp lý mang lại hiệu quả kinh tế và có tính khả thi cao.

\section{Đóng góp của các tác giả}

Nguyễn Văn Thịnh, xây dựngý tưởng, bố cục, phân tích, biên tập và hiệu đính.

\section{Tài liệu tham khảo}

Deloitte, (2013). Guide to Fiscal Information. In Key Economies in Africa, p.15-22.

Lubiantara, B, (2005a). Marginal Field Incentive. p.2. Lubiantara, B, (2005b). The Analysis of the Marginal 
Field Incentive - Indonesia Case, 1-2.

Partowidagdo, W, (1996). Incentives for Marginal

Field Development in Indonesia. 25th Annual Convention Proceedings (Volume 3).

Nguyễn Vũ Trường Sơn, Từ Thành Nghĩa, Cao Tùng Son, Pham Xuan Sơn, Le Thi Kim Thoa, Le Viet Dung, Nguyễn Hoai Vu, Ngo Hưu Hai, Nguyễn Thuc Khang, Nguyễn Quang Vinh. (2017). Giai phap khai thac dau kh cho cac mo nho, can bien, Tạp chí dầu khí số 5/2015, pp 32-37.

Phùng Đình Thực, Hà Văn Bích, Tống Cảnh Sơn, Lê Đinh Hoe, Vưigovskoi V.P. (2002). Qua trinh hınh thành và phát trien he thong thu gom, xư lý và van chuyen dau khı tai các mo cua XNLD VIETSOVPETRO, Tuyển tập hội nghị khoa họckỹ thuật dầu khí kỷ niệm 20 năm thành lập XNLD Vietsovpetro và khai thác tấn dầu thú 100 triệu, 113-118.

Sagex Petroleum AS. (2005). Field Developments and Technical Solutions Marginal Fields - Norwegian Experiences. Petroleum Policy and Management Project - The 3rd Workshop Indonesia Kutei Basin Case Study, p.2.

Svalheim, S. (2004). Marginal Field Development-a
Norwegian Perspective. The 3rd PPM Seminar, 20.

Tăng Văn Đồng, Nguyễn Thúc Kháng, Nguyễn Hoài $\mathrm{Vu}$, Le Viet Dung. (2017b). Khai thac khı thien nhien va thu gom khı đong hanh tư cac mo nho/can bien, Tạp chí dầu khí, 5, 29-36.

Tăng Văn Đồng, Trần Anh Quân, Trần Đình Kiên, Nguyễn Thuc Khang, Tran Ngoc Tuan, Pham Trung Son, Nguyễn Văn Trung. (2017a). Giai pháp đưa mot so mo nho can biên trên them luc đia Nam Viet Nam vào khai thác, Tạp chí Khoa học Kỹ thuật Mỏ - Địa chất, 58(2), 154-164.

Tống Cảng Sơn, Lê Đình Hoè. (2015). Kinh nghiệm vận chuyển dầu nhiều paraffin bằng đường ống ở các mỏ ngoài khơi của liên doanh Việt Nga- Vietsovpetro, Tạp chíd dầu khí số 2/2015, pp 43-52.

Vũ Minh Đức. (2015). Nghiên cứu quy hoạch phát triển tổng thể các mỏ dầu khí bể Cửu Long trên cơ sở tối ưu hóa hệ thống công nghệ và thiết bị khai thác hiện hữu, Tổng Công ty Thăm dò Khai thác Dầu khí(PVEP).

Warlick, D. (2007). A new era for marginal oil production. Oil \& Gas Financial Journal. 